\title{
Hand, foot and mouth disease; a report of recent epidemic and review of literature
}

\author{
RW Ragunathan ${ }^{1}$, RLM Pushparani ${ }^{2}$ \\ Consultant Dermatologist ${ }^{\prime}$, Registrar Dermatology ${ }^{2}$, Teaching Hospital, Karapitiya, Galle. \\ e-mail address of the correspondingauthor,Dr.R.W.Ragunathan: muruguragu@gmaill.com
}

Hand, foot and mouth disease (HFMD) is a human syndrome caused by intestinal viruses of the Picornaviridae family, most commonly by Coxsackie A16 and Enterovirus $71^{1}$.

HFMD is a mild, but highly contagious disease. It spread from person to person usually through unwashed hands, contaminated surfaces ${ }^{2}$ or direct contact with the mucus, saliva or faeces of an infected person. Disease is most common in children as in child caresetting where diaper changing and potty training are constant, and little hands often are in and out of the mouth frequently. HFMD also spreads through fluid from blisters and a mist of fluid sprayed in the air when infected person cough or sneezes ${ }^{2}$.

Although less common, because most adults have strong enough immunity to defeat the virus, HFMD can occur in adolescents and adults. Outbreaks of HFMD have occurred in communities of adults ${ }^{3}$.

Symptoms and signs of HFMD include, fever, sore throat, headache, fatigue, malaise, painful oral lesions, (on the tongue and mouth) non-itchy body rash, followed by sores with blisters on palms and soles, sores or blisters on the buttocks of small children and infants, irritability in infants and toddlers, loss of appetite and diarrhea in some.

Incubation period is 3-7 days. Fever is often the first sign and is of low grade, usually followed by a sore throat, sometimes with poor appetite and malaise ${ }^{2}$. This prodrome may be absent or mild and occur 1-2 days before oral and skin lesions. Cutaneous manifestations are seen in $100 \%$ infected persons. The first lesions involve the oral mucosa and are most commonly seen on the buccal mucosa and tongue whilst the palate, uvula and anterior tonsillar pillars are affected in up to one third of cases. Characteristic grey-white vesiculo-pustules (Figure 1) are most commonly seen on the palms and soles or

Galle Medical Journal, Vol 14: No. 1, September 2009 on the dorsal or lateral surfaces of the hands and feet ${ }^{4}$. Vesicles are usually up to $5 \mathrm{~mm}$ in diameter, few in number, although there may be 50 or more and fade over 2-3 days ${ }^{3}$. These vesicles are flaccid, thin walled and often asymptomatic although they can be painful or pruritic. Lesions rapidly form sharply marginated erosions and ulcerations often with an erythematous base and then become crusted. Usually most other areas are spared. It is not unusual to find a macular papular and vesicobullous eruption on the buttock and genitalia. In an atopic infants generalized vesicle resemble Kaposi's varicelliform eruption ${ }^{3}$.

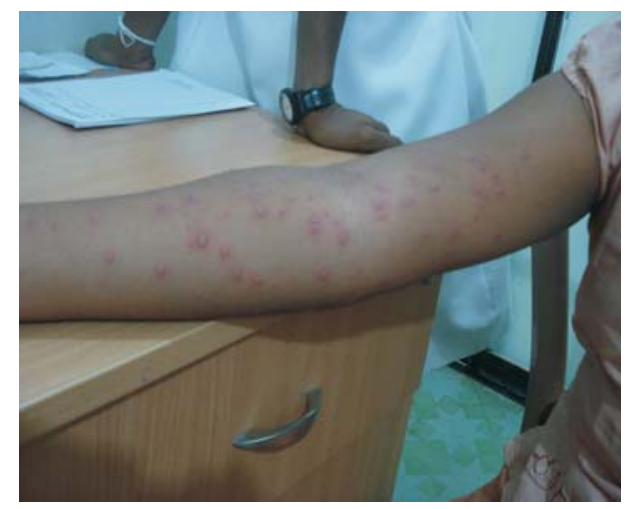

Figure 1 - Forearm with classical vesicles

Diagnosis of HFMD is purely clinical although throat swab or stool specimen can be tested to determine the virus. Usually there are no complications from HFMD and lesions heal well with no sequelae. There is no specific treatment for HFMD. Individual symptoms such as fever and pain from sores may be eased with symptomatic therapy.

Certain precautions such as washing hands carefully, disinfecting common areas, teaching children how to practice good hygiene and isolating contagious people can help to reduce the chances of infection with HFMD. Eating ice cream, drinking 
cold beverages such as milk or ice water, avoiding acidic, salty or spicy foods and rinsing mouth with warm salt water may help in reducing sore mouth. HFMD appeared in epidemic proportions during April- June every year at least for the last few years, probably with increasing severity. We report a recent epidemic of HFMD seen in Galle.

\section{Aim of the study}

To illustrate the clinical pattern of the disease in order to increase the awareness among medical professionals.

\section{Method}

All patients who presented to the Dermatology unit, Teaching Hospital, Karapitiya and those who were referred form Medical and Paediatric units were included in the study. All patients were examined by either of authors or by both. Detailed history was taken and examination done to look for clinical features, their chronological order and distribution of skin lesions in addition to demographic data.

\section{Results}

There were total of 36 patients. Eighteen (50\%) were below 12 years, out of which 8 were infants. Five were between $1-2$ years of age. Out of $18(50 \%)$ adults, 12 were between 13-30 years of age. There were 21 male and 15 females.

Except for 5 patients all the others presented with fever (Table 1). Out of the 5 patients who did not present with fever, 3 were adults. Almost all had involvement of hands (Figure 2) and feet (Figure 3). Mouth involvement (Figure 4) was less common (61\%). Trunk was affected in $78 \%$. Eighty three percent of children had buttock lesions (Figure 5) and this was less common in adults. Face was affected in some (Figure 6). Itching was a prominent feature in some (17\%). Scalp lesions were seen mainly in children. These data are shown in table 2. Some had very mild disease while others had very extensive disease (Figure 7). Many had lesions very much suggestive of chickenpox.

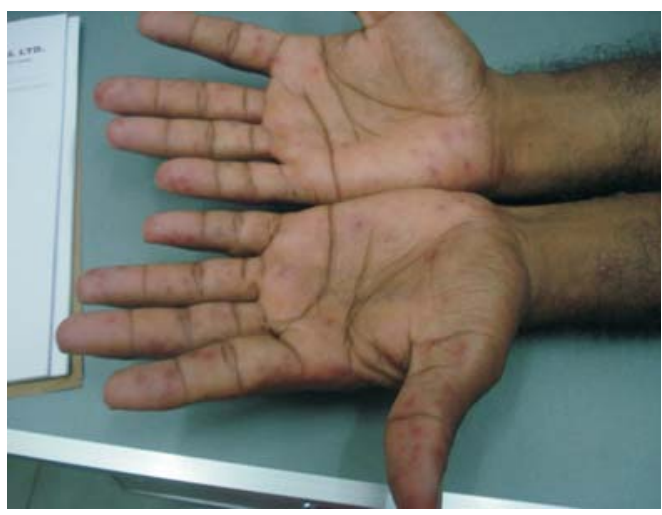

Figure 2 - Hands with vesicles

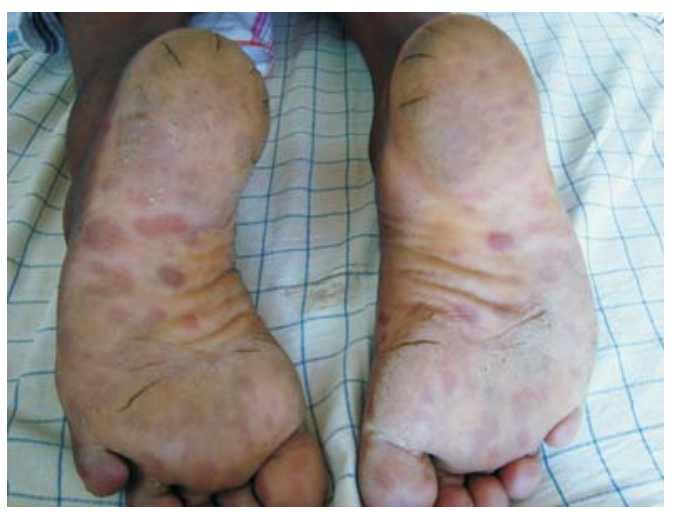

Figure 3 - Feet with vesicles

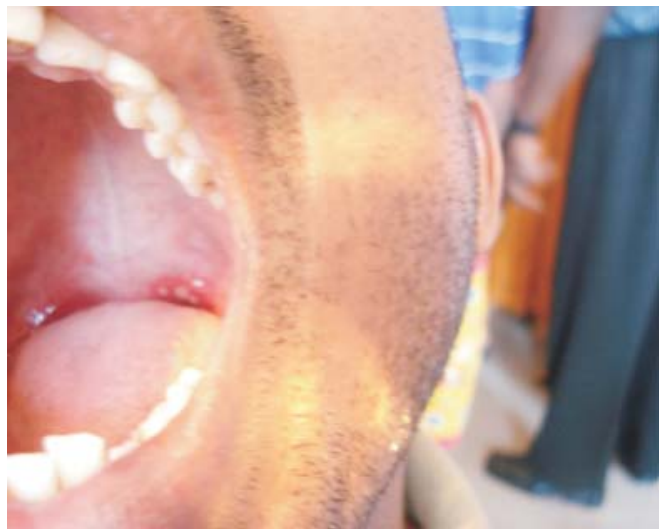

Figure 4 - Mouth showing vesico-pustules with surrounding erythema

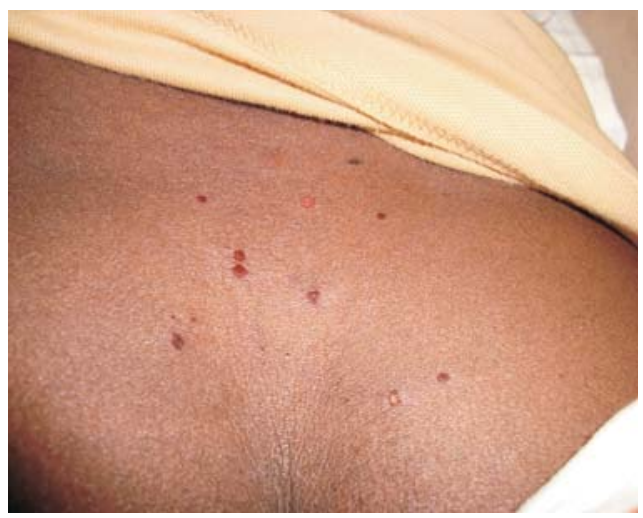

Figure 5 - Involvement of buttocks 


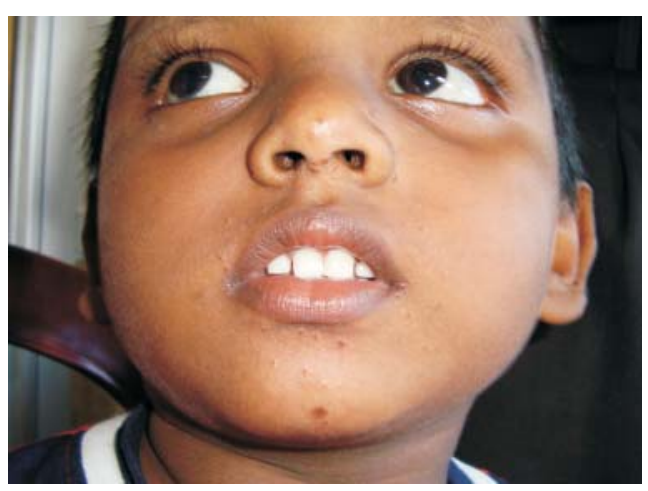

Figure 6 - Lesions surrounding mouth

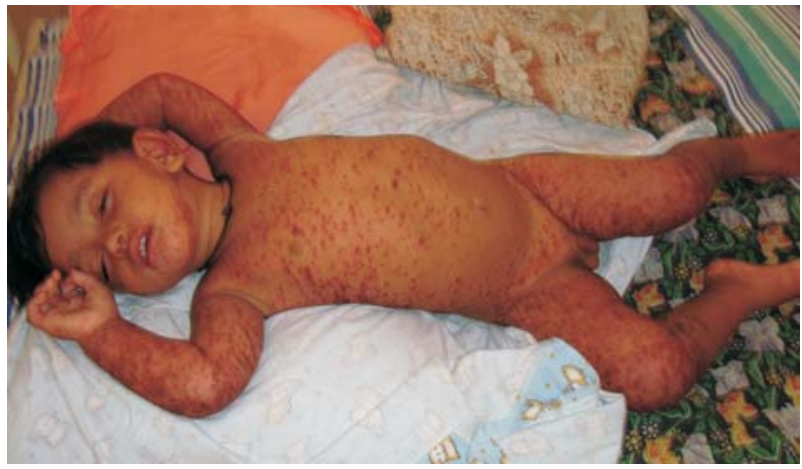

Figure 7 - Kaposi varicelliform like eruption

Table 1: Clinical features according to the age

\begin{tabular}{|l|c|c|}
\hline \multirow{2}{*}{ Feature } & \multicolumn{2}{|c|}{ Age } \\
\cline { 2 - 3 } & $<\mathbf{1 2}$ years & $>\mathbf{1 2}$ years \\
\hline Fever & 16 & 15 \\
\hline Itching & 3 & 5 \\
\hline Extensive disease & 6 & 3 \\
\hline
\end{tabular}

Table 2: Site of lesion according to the page

\begin{tabular}{|l|c|c|}
\hline \multirow{2}{*}{ Site of lesion } & \multicolumn{2}{|c|}{ Age } \\
\cline { 2 - 3 } & $<\mathbf{1 2}$ years & $>\mathbf{1 2}$ years \\
\hline Scalp & 5 & 1 \\
Hand & 17 & 17 \\
Feet & 17 & 16 \\
Mouth & 9 & 13 \\
Trunk & 15 & 13 \\
Buttocks & 15 & 11 \\
\hline
\end{tabular}

\section{Discussion}

Our sample does not completely represent the severity of the epidemic especially because many children would have been managed by Paediatricians. It may be due to the same reason why we have only $50 \%$ children whereas HFMD is a disease common in children with adults rarely affected $^{1}$. Though the name implies hand foot and mouth disease $49 \%$ did not have mouth lesions. As seen in other reports ${ }^{2}$ fever was the presenting symptom and it was mild in most of our patients. Most of our patients had skin involvement starting on the $2^{\text {nd }}$ to $3^{\text {rd }}$ day of the illness as is commonly seen. Like other reported cases most of our patients also had milder disease which subsided over 7 days. Though some atopic children had severe disease resembling Kaposi varicelliform eruption in some series $^{3}$, some of our children had picture similar to chicken pox.

As seen in other reports ${ }^{3}$ buttock involvement as well as generalized forms were seen in some of our patients. Itching was not a prominent feature in other reports though it was a prominent feature in some of our patients. Though few of our patients had scalp involvement it has not been described in other series. All affected patients were treated symptomatically. They were also advised regarding hygiene. Parents were advised the ways the disease can spread and to minimize spread among family members.

\section{Conclusions}

Hand foot and mouth disease is not an uncommon problem and could be distressing to some. Disease could be much more extensive and wide spread than the name implies as seen in this epidemics.

\section{References}

1. Hand, foot and mouth disease. http://en.wikipedia.org/wiki/Hand,_foot_and_mouth_dis ease. Accessed on 02.07.2009.

2. H a n d - foot - a n d - mouth dise a s e http://www.mayoclinic.com/health/hand-foot-andmouth-disease/DS00599. Accessed on 02.07.2009.

3. Sterling JC, Kurtz JB. Viral infections. In: Rook, Wilkinson, Ebling. Text book of Dermatology $6^{\text {th }}$ ed, Blackwell Science, vol 2, 1998: p1086.

4. Bernice R Krafchik. Viralexanthems. In: Harper J, Oranje A, Prose N. Textbook of Paediatric Dermatology, $1^{\text {st }}$ ed, vol 1, Blackwell Science 2000: p345. 